\title{
As bibliotecas universitárias na Sociedade do Conhecimento: \\ O IMPERATIVo da COLABoraÇão
}

\author{
Maria João Amante \\ Biblioteca do ISCTE-IUL - Instituto Universitário de Lisboa
}

Ana Isabel Extremeño Placer

Facultad de Documentación de la Universidad de Alcalá

António Firmino da Costa

Departamento de Sociologia do ISCTE-IUL - Instituto Universitário de Lisboa

\section{Resumo}

O ensino, a aprendizagem e a investigaçáo constituem funçôes centrais nas instituiçôes de Ensino Superior. A missão das Universidades consiste em preparar cidadáos capazes de responder aos desafios e exigências colocados pela Economia do Conhecimento. Para a concretizar, a introdução de mudanças e melhorias nestas organizaçôes constitui um imperativo.

As instituiçôes de Ensino Superior devem preparar os seus diplomados com as competências, conhecimentos e resultados de aprendizagem que promovam o desenvolvimento individual e de que a sociedade necessita de forma a garantir o desenvolvimento económico, social e cultural. Neste sentido, o enfoque na educaçáo está a mudar, deslocando-se dos resultados do ensino para a aprendizagem em si mesma, maximizando os esforços dos aprendentes. O desenvolvimento do Espaço Europeu de Ensino Superior (EEES) exige novas formas de trabalhar aos estudantes, aos professores e aos bibliotecários. Os bibliotecários devem actuar como agentes inovadores que introduzem mudanças com o objectivo de ajudar a Universidade a responder às novas exigências do Ensino Superior. Acreditamos que, neste contexto, o ensino e a aprendizagem terão lugar com recurso a relaçôes colaborativas pois são necessárias abordagens multidisciplinares para alcançarmos os melhores resultados. Esta abordagem é particularmente importante no que concerne a colaboração entre professores e bibliotecários.

\begin{abstract}
Teaching, learning and research are core functions of all higher education institutions. Universities' mission is to prepare a workforce capable of meeting the demands of the knowledge economy. To perform this task, the need for changes and improvement in higher education is an imperative. Higher education institutions should prepare their graduates with skills, knowledge and learning outcomes that promote individual development and that the society needs to guarantee economic, social and cultural development. In this sense, the focus on education is changing from the results of teaching to the learning itself, maximizing the efforts of learners. The development of the European Higher Education Area requires new ways of working in the university for students, for teaching faculty and for librarians. Librarians introduce changes in order to help the university to respond to the new realities of higher education. The most important, perhaps the dominant way of teaching and learning will require collaborative relationships. An interdisciplinary approach is needed to get the adequate solutions. This
\end{abstract}


approach is particularly important in what concerns collaboration between teaching faculty and librarians.

\section{Introdução}

A missão das Universidades consiste em preparar cidadáos capazes de responder aos desafios e exigências colocados pela Economia do Conhecimento. A sua concretização depende da introdução de mudanças e melhorias. Decorrem, entre outros, dos seguintes aspectos: restriçôes financeiras com que se confrontam as instituiçôes de Ensino Superior, exigências da sociedade em termos de resultados e de produtividade, algum criticismo quanto às políticas para o Ensino Superior, aumento no número de estudantes neste nível de ensino bem como a sua crescente diversidade, competição à escala internacional, impacto das tecnologias de informação e alteração nos padróes de acesso, envolvimento e expectativas dos estudantes. Numa economia baseada no conhecimento, a produtividade e a competitividade dependem da capacidade das organizaçóes para processar informaçáo de forma eficiente e para produzir conhecimento. O bem-estar da sociedade depende da qualidade da educação e da formação e da integração da totalidade da população neste sistema.

As instituiçóes de Ensino Superior devem preparar os seus diplomados com as competências, conhecimentos e resultados de aprendizagem que promovam o desenvolvimento individual e de que a sociedade necessita para garantir o desenvolvimento económico, social e cultural. Assim, o enfoque na educação está a mudar, deslocando-se dos resultados do ensino para a aprendizagem em si mesma, maximizando os esforços dos aprendentes. O desenvolvimento do Espaço Europeu de Ensino Superior (EEES) exige novas formas de trabalhar aos estudantes, aos professores e aos bibliotecários. Os estudantes devem mudar a sua forma de estudar e aprender, reforçando a sua autonomia na aprendizagem. O papel dos professores será o de acompanhar e orientar os estudantes neste processo. Os bibliotecários são um componente fundamental neste novo modelo de ensino aprendizagem pois possuem as competências e o conhecimento necessário para adaptar as bibliotecas universitárias ao novo ambiente de aprendizagem promovido pelo EEES.

\section{O Ensino Superior na Europa do Conhecimento}

A Agenda de Lisboa apela à participação dos vários sectores da sociedade na concretizaçáo do objectivo estratégico de tornar a Europa “... no espaço económico mais dinâmico e competitivo do mundo baseado no conhecimento e capaz de garantir um crescimento económico sustentável, com mais e melhores empregos, e com maior coesão social." (Conselho Europeu de Lisboa, 2000). Neste processo, as instituiçôes de Ensino Superior desempenham um papel muito relevante "...debido a su doble misión tradicional de investigación y enseñanza, a su papel cada vez más importante en el complejo proceso de innovación, así como a sus demás aportaciones a la competitividad de la economía y a la cohesión social, por ejemplo, su función en la vida ciudadana y en materia de desarrollo regional." (Comisión Europea, 2003, p. 
2). A Economia e a Sociedade do Conhecimento apoiam-se na produção do referido conhecimento, sobretudo através da investigação científica, na sua transmissão e divulgação através da educação, formação e novas tecnologias, e na sua exploração através da inovação tecnológica. As Universidades asseguram um importante papel em todas estas dimensóes. São um elemento-chave na concretização da Europa do Conhecimento.

Pelo exposto, a União Europeia necessita de uma comunidade universitária forte e próspera numa universidade de excelência. Contudo, as instituiçóes de Ensino Superior sofrem as pressóes de dinâmicas sociais e económicas externas as quais "...actuam com intensidade crescente na exigência de mudanças sobre: a natureza do ensino e os métodos de aprendizagem; a investigação e a sua articulação com o ensino e a inovação; a natureza do relacionamento institucional com a sociedade." (Simão, Santos e Costa, 2003, p. 63). Da reflexão sobre estes temas resultaram várias Comunicaçóes da Comissão e do Conselho para os Estados-Membros com recomendaçóes sobre as questôes anteriormente enunciadas. A sua adopção traduziu-se em mudanças, por vezes profundas, nos conteúdos e na estrutura dos sistemas de Educação Superior destacando-se questóes como o financiamento, a garantia da qualidade e a avaliação das referidas instituiçôes. Além disso, os sistemas de Educação Superior dos EstadosMembros confrontam-se com um conjunto de tendências: ameaças ou oportunidades, conforme forem enfrentadas. Destacamos a procura de formação superior numa lógica de aprendizagem ao longo da vida, a internacionalização da educação e da investigaçáo, a necessidade de uma cooperação estreita entre universidades e empresas, a multiplicação dos lugares de produção de conhecimento, a reorganização dos conhecimentos e o aparecimento de novas expectativas.

Com a Declaração da Sorbonne, em 1998, teve início um processo de convergência dos sistemas nacionais de Educaçáo Superior com o objectivo da criaçáo do Espaço Europeu de Ensino Superior (EEES). Esta Declaração “...subraya el protagonismo de las universidades en el desarrollo de la dimensión cultural europea. Comienza, entonces, un proceso cuyo objetivo es construir un espacio de educación superior como instrumento clave de la movilidad de los ciudadanos y de la construcción de un mercado laboral unificado." (Moscoso Castro, 2006, p. 11). Projectos entretanto desenvolvidos, como o Tuning - sintonizar as estruturas educativas da Europa (2000), serviram para demonstrar que as Universidades, para além de transferirem conhecimento consolidado também apoiam o desenvolvimento de diferentes competências genéricas. Por isso devem promover um ensino-aprendizagem que estimule, nos estudantes, o desenvolvimento da capacidade de análise e de síntese, a independência de critério, a curiosidade, o trabalho de equipa e a capacidade para comunicar.

Assim, "Bolonha significa não só aumentar a participação do estudante no processo de aprender, de reestruturar a forma e a quantidade do tempo de formação, mas mais significativo ainda é a mudança que supóe do ponto de vista metodológico." (Silva, Fernández Marcial e Martins, 2007). Isto significa que "El espiritú del EEES refuerza (...) la necesidad, por parte especialmente de los estudiantes, de un uso más intensivo de los recursos que la universidad pone a su disposición." (Cabo Rigol e Espinós Ferrer, 2004, p. 2). Como consequência, abrem-se novas perspectivas de trabalho para as bibliotecas e para os bibliotecários. 


\section{As bibliotecas universitárias no contexto do Ensino Superior Europeu}

Devemos analizar as bibliotecas universitárias tomando em consideração o contexto, isto é, a própria Universidade. Devem, pois, ser consideradas como unidades que contribuem para a reputação da Universidade devendo estar alinhadas com a sua missão, participar no desenvolvimento do currículo em matérias relacionadas com as competências em literacia informacional e integrar espaços e funçôes destinados à aprendizagem dos estudantes (Weiner, 2009, p. 9). Por outro lado, o seu estudo deve considerar a cultura organizacional, entendida como o conjunto de valores e de crenças existentes na Universidade, os quais condicionam a relação da biblioteca com os outros membros da comunidade académica: gestáo, serviços de apoio, professores, estudantes, entre outros. As bibliotecas universitárias necessitam de flexibilidade organizacional, maior enfoque no utilizador, reforço dos membros da equipa e sua satisfação no trabalho, melhoria dos processos de gestão, comunicação, coordenaçãa e planificação. A penetração das TIC, a explosão dos conteúdos de informação digitais, os projectos de digitalizaçáo e a Internet implicam transformaçóes no ensino e na aprendizagem, na comunicaçáo académica e no papel tradicional dos serviços de informação. Estes desafios criam um ambiente dinâmico que os bibliotecários devem entender como uma oportunidade.

Porque as bibliotecas devem apoiar as políticas e as práticas das instituiçóes em que estáo inseridas, a compreensão da evolução do Ensino Superior é indispensável para a evolução da própria biblioteca. Nesta linha se pronunciam Moscoso Castro (2006) y Orera Orera (2007) para quem "La razón de ser de la biblioteca universitaria es de servir de apoyo a la universidad en el desarrollo de sus funciones. Para que resulte eficaz, debe existir una integración entre ella y la misión, fines y objetivos de la universidad." (p. 335). Trata-se de garantir o futuro da biblioteca através do alinhamento dos seus objectivos estratégicos com as exigências do contexto numa época marcada por alteraçóes rápidas e amplas. As exigências a que a Universidade está submetida tendo em vista a criação do EEES até 2010, traduzem-se em novas funções, num papel mais activo e numa maior integração da biblioteca na Universidade.

Pelo exposto, as exigências de qualidade e avaliação que se colocam às Universidades (cujos objectivos são a transmissão da cultura, o exercício da docência e da investigação científica, a socialização dos seus estudantes e o compromisso social) estendem-se às suas bibliotecas tornando clara a necessidade da recolha de evidências sobre como e em que medida as bibliotecas contribuem para facilitar os processos de aprendizagem dos estudantes.

A pedagogia que decorre do Processo de Bolonha assenta na aprendizagem mais do que no ensino, nos estudantes mais do que nos professores, nas competências e não apenas nos conhecimentos, no trabalho do estudante mais do que em aulas magistrais e na aprendizagem ao longo da vida mais do que no enciclopedismo (Adell, 2005). A formação universitária centrada no desenvolvimento de competências (entendidas como conhecimentos, atitudes e capacidades) e náo na aquisição e acumulação de conhecimentos temáticos especializados é, agora, encarada como fundamental para o percurso académico, profissional e pessoal. $\mathrm{O}$ interesse pelo desenvolvimento de competências constitui uma resposta aos novos desafios económicos e sociais colocados pela Sociedade do Conhecimento, em que as TIC originam uma nova estrutura social 
e um novo modelo de sociedade. Assim, o ambiente de aprendizagem que é necessário construir deve possuir as seguintes características: “...being student-centered; being interactive and dynamic; enabling group work on real world problems; enabling students to determine their own learning routes; emphasizing competencies like information literacy to support lifelong learning." (Roes, 2001, p. 3).

Estas mudanças têm repercussóes no trabalho desenvolvido por professores e estudantes. Para os primeiros, o que se denominava "carga docente" deve agora denominar-se "actividade académica", onde se incluem as horas de aulas, o tempo dedicado à preparação das mesmas, a organização, orientação e supervisão do trabalho dos estudantes, a preparação dos exames e de materiais didácticos. Os segundos devem modificar os seus hábitos de estudo e de aprendizagem, demasiado centrados nas aulas, nos apontamentos e na bibliografia recomendada pelos professores. $\mathrm{O}$ modelo educativo proposto por Bolonha e a nova unidade de medida, o crédito europeu (ECTS) assentam no trabalho do estudante e não unicamente no número de horas de aulas o que significa que se centram na aprendizagem dos estudantes e não na docência dos professores. Trata-se de aprender a aprender, num modelo que lhes exige maior autonomia e responsabilidade pelo seu processo educativo. Este modelo deve capacitá-los para a aquisição de estratégias e instrumentos que lhes permitam continuar a aprender, para manterem os conhecimentos actualizados e, assim, garantirem a empregabilidade e mobilidade. Aumenta a sua liberdade quanto ao momento, lugar e forma de aprender, tendo a Internet contribuído para uma aprendizagem mais aberta e interactiva. Neste quadro, quer as bibliotecas universitárias quer os seus profissionais vêem renovada e reforçada a importância da sua actuação devendo orientar os estudantes num processo de aprendizagem marcado por uma maior autonomia. As bibliotecas renovam a sua importância devido ao novo paradigma educativo, agora mais do que nunca centrado no estudante.

Para as bibliotecas universitárias, estar centrado nos estudantes significa construir um espaço virtual de informação para além do espaço físico ao qual os estudantes podem aceder e encontrar recursos de informaçáo com qualidade controlada pela própria biblioteca. Significa constituir-se como um centro de aprendizagem activo. Por outro lado, as necessidades de informação e a forma como é utilizada pelos estudantes mudam com o passar do tempo, motivo pelo qual é indispensável que a biblioteca acompanhe esta mutação e, sempre que possível, a antecipe. No novo ambiente educativo, o estudante necessita de utilizar as TIC para identificar, aceder e seleccionar a informação mais adequada às suas tarefas; deve estar capacitado para avaliar e incorporar a informação recuperada; necessita de espaços físicos e virtuais; precisa de horários alargados e, sobretudo, de desenvolver hábitos de trabalho autónomo. A expansão e a diversificação dos públicos que acedem ao Ensino Superior repercute-se na biblioteca universitária, obrigando-a a um esforço continuado (que deve ser proactivo) de introdução de mudanças no seu funcionamento, de criação de novos projectos e actividades, com o objectivo de responder e, sempre que possível, antecipar a resposta às necessidades de informação colocadas pelos destinatários da sua actuação.

Para garantirem a sua relevância no campus e na vida académica, as bibliotecas universitárias devem desenvolver as seguintes acçóes: evoluir de organizaçóes centradas no livro para organizaçôes entendidas pelos seus utilizadores como facilitadoras de acesso à informação de qualidade em vários suportes; a cultura das bibliotecas e 
dos seus profissionais deve afirmar-se como uma cultura de serviço e de orientação ajudando os utilizadores a encontrar a informação de que necessitam; e devem desempenhar os seus papéis de forma mais activa, no contexto da Universidade assim como no contexto de um mercado de disseminação e fornecimento de informação crescentemente competitivo (ACRL, 2007). Uma actuaçáo mais proactiva e integrada é, assim, determinante para que a biblioteca alcance uma maior centralidade e um posicionamento estratégico na Universidade.

Este aspecto merece destaque pois, apesar de algum êxito no desempenho da sua missão e da referência frequente à biblioteca como o "coração da Universidade" a verdade é que o papel de apoio ou suporte assumido pela Biblioteca não a transformou "...into a truly bona fide academic participant in the processes of teaching and assessing learning. It has definitely not given the library a more central educational role, one that in the academy's tradition of acknowledged centrality is usually expressed in the credit bearing status that is accorded those intellectual activities and content officially endorsed by the academy." (Owusu-Ansah, 2007, p. 418). Apesar de todo o trabalho desenvolvido ao longo de décadas, sempre com o enfoque no utilizador, o posicionamento da biblioteca na Universidade é frequentemente de unidade administrativa ou de apoio e não de unidade produtora ou facilitadora da produção de conhecimento.

O desenvolvimento do modelo educativo de Bolonha coloca as bibliotecas universitárias numa posição muito favorável. A sua principal missão sempre foi organizar e representar o conhecimento que se expressa e difunde sob a forma de informação registada, independentemente do suporte material e do seu local de depósito. Desta forma, apoiam a aprendizagem ao longo da vida, influenciam a aprendizagem e o pensamento crítico e têm impacto na aprendizagem dos estudantes. Para garantir um papel activo para a biblioteca devem ser desenvolvidos cinco eixos estratégicos: migrar dos recursos impressos para os digitais; diminuir o volume dos recursos impressos permitindo ganhar espaço na biblioteca para outras finalidades; desenvolver os espaços existentes na biblioteca com o objectivo de criar os information ou academic commons ou CRAI - Centros de Recursos para el Aprendizaje e Investigación. Isto significa que a biblioteca deve assumir-se e ser assumida na Universidade como um centro de conhecimento e de aprendizagem na medida em que "...is the intellectual commons for the community where people and ideas interact in both the real and virtual environments to expand learning and facilitate the creation of knowledge." (ARL, 1999, p. 3).

\section{O bibliotecário na Universidade}

As mudanças que marcam o quotidiano das Universidades actualmente e os desafios que enfrentam têm impacto nas bibliotecas obrigando a um questionamento e a uma avaliação quanto aos serviços prestados, com o objectivo de garantir a sua adequação aos destinatários. O mesmo se passa com os papéis desempenhados pelos bibliotecários. Isto significa que a resposta aos desafios colocados às bibliotecas universitárias exige aos bibliotecários que reflictam sobre a natureza, os objectivos e a missão das bibliotecas e também sobre os seus conhecimentos, competências e papel profissional nestas organizações tendo em vista a construção de ambientes de informação virtuais e o fornecimento de serviços de valor acrescentado aos seus utilizadores. 
Papéis entendidos como mais tradicionais, como o tratamento, organização, recuperaçáo, difusão da informação ou a gestão e desenvolvimento das colecçôes, viram aumentado o seu grau de complexidade. Outros, como o de formador, reforçam a sua importância devido a aspectos como as exigências colocadas pelo novo modelo educativo (que pressupóe novas metodologias de ensino), às mudanças ocorridas nos espaços de aprendizagem (que passaram de presenciais a semi-presenciais ou totalmente virtuais, através do e-learning), ao aumento exponencial da informação disponível, entre outros. O bibliotecário deve, assim, actuar como um gestor e um líder “...meaning expectations associated with the scope and complexity of the task expanded to include marketing, community outreach, consensus building, and fundraising activities (Weinberg et al., 2005, p. 299).

$\mathrm{Na}$ linha de investigação que temos desenvolvido, consideramos que esta reflexão deve partir, por um lado, da noçáo da biblioteca como serviço ao público e do desaparecimento do monopólio da informação que teve durante séculos. Por outro lado, do reconhecimento da necessidade de os bibliotecários assumirem um papel mais activo nos processos de aprendizagem e de investigação. Tal implica analisar o contexto e antecipar produtos e serviços, significa assumir novos papéis profissionais sabendo que se não o fizerem outros o farão. Neste sentido, para reafirmar um novo posicionamento profissional e ampliar as suas competências devemos "... redirect our priorities, collaborate, take risks, and reinvent our organizations." (Stoffle et al., 2000, p. 895).

Os bibliotecários actuam, assim, como facilitadores da inovação organizacional contribuindo para a melhoria contínua da qualidade dos serviços de informação através do desenvolvimento de estratégias de actuação colaborativas orientadas para o conhecimento. Os esforços que desenvolvem, tendo em vista a mudança e melhoria dos espaços em que usam e desenvolvem as suas competências, conhecimento e capacidades, têm sempre presentes as necessidades dos utilizadores e a crença em que a formação e a gestão do conhecimento são missões centrais nas bibliotecas universitárias. Como resultado desta actuação, as bibliotecas universitárias e os seus profissionais apoiam a aprendizagem colaborativa, a aprendizagem através do estabelecimento de parcerias, aumentam a flexibilidade das relaçóes organizacionais, aproveitam a sinergia da informação e criam valor. Na medida em que os domínios de actuaçáo da Universidade se centram no ensino, na investigação e na prestação de serviços à sociedade, também o papel das bibliotecas e dos seus profissionais deve integrar-se nestes domínios, motivo pelo qual o leque de conhecimentos e de competências dos bibliotecários deve ser ampliado.

Ao pensar sobre os papéis que os bibliotecários assumem ou podem assumir na Universidade consideramos as seguintes dimensôes: como gestor de colecçóes, prestador de serviços, produtor de metadados, fornecedor de serviços de referência virtuais, mediador e validador da informação, analista simbólico, formador em literacia informacional e facilitador da aprendizagem, gestor do conhecimento e editor de conteúdos, formador em Direito de Autor, gestor de relacionamentos e dinamizador de acçóes culturais. Das dimensóes enunciadas destacamos duas, o papel de formador em literacia informacional e facilitador da aprendizagem e o de gestor do conhecimento e editor de conteúdos. O primeiro resulta das exigências que se colocam devido ao aumento exponencial da informação disponível, à variedade dos recursos de informação 
e, sobretudo, às alteraçóes a que estão submetidas as metodologias de ensino, mais centradas no estudante e, segundo as quais, este deve dedicar mais tempo ao estudo individual, em que o professor actua como um tutor, devendo o estudante identificar a informação de que necessita para realizar os seus trabalhos académicos. Esta dimensão está também directamente vinculada à necessidade de preparar os estudantes para a aprendizagem ao longo da vida. Neste processo a biblioteca assume um papel destacado assim como aqueles que nela trabalham sendo, agora mais do que nunca, chamados a participar no processo de formação dos estudantes. A segunda perspectiva é uma consequência do papel que as bibliotecas e os seus profissionais assumem no domínio da gestáo do conhecimento, nomeadamente, do conhecimento organizacional, e na reforma do sistema de comunicação científica no âmbito do movimento de Acesso Livre ao Conhecimento, como promotores da edição de revistas em acesso livre e da constituição de Repositórios Institucionais.

Acreditamos que, neste contexto, o ensino e a aprendizagem terão lugar com recurso a relaçóes colaborativas pois são necessárias abordagens multidisciplinares para alcançarmos os melhores resultados. Esta abordagem é particularmente importante no que concerne à colaboração entre professores e bibliotecários. Devido ao seu posicionamento na Universidade, os bibliotecários têm a oportunidade de contribuir, de forma positiva, para os processos de ensino, aprendizagem e investigação que aí têm lugar. Mas devem igualmente admitir que, por vezes, as suas competências, capacidades e conhecimento não são reconhecidos ou, pelo menos, conhecidos nas instituições de Ensino Superior em que trabalham, nomeadamente pelos professores.

\section{O binómio bibliotecário-professor}

$\mathrm{Na}$ Sociedade do Conhecimento a forma mais comum de trabalhar é em rede, falando-se até de redes virtuais de comunicação. Na Universidade existem vários grupos profissionais que não podem continuar a trabalhar de forma isolada sob pena de não ser concretizada a missão da Universidade e concretizados os seus objectivos, com particular destaque para os relacionados com a formação académica dos estudantes.

As exigências de Bolonha obrigam os professores a reavaliar tanto o conteúdo como os planos de estudos de várias disciplinas, assim como a forma de as ensinar. Por outro lado, é certo que as Universidades estão a preparar os seus graduados para um futuro marcado pela incerteza, o que significa que estes necessitam de adquirir competências e capacidades que lhes permitam viver e trabalhar num contexto com essas características. Doskatsch (2003) entende que a biblioteca e os seus profissionais podem apoiar a reengenharia do contexto de ensino-aprendizagem através da descoberta de recursos que apoiem desenvolvimento do currículo, da promoção da integração da literacia em informação no mesmo, do desenvolvimento colaborativo com os professores de um conjunto de recursos de aprendizagem online, da sua actuaçáo como intermediários/ facilitadores para apoiar o acesso aos recursos e aos serviços num ambiente informativo marcado pela complexidade, da promoçâo de um acesso rápido e fácil aos recursos e aos serviços de informação e da participação dos bibliotecários nos comités para o desenvolvimento do currículo (p. 112-113). A Universidade constitui um ambiente favorável ao estabelecimento de parcerias entre os bibliotecários e os professores pois 
é reconhecido que ambos têm objectivos comuns “... namely to engage students in critical-thinking, discipline-oriented learning that depends on the organization of knowledge, and an understanding of disciplinary and interdisciplinary discourses." (Hutchins, 2005, p. 16).

Existe extensa literatura que aponta a colaboração entre estes dois grupos como a chave para o êxito da formação dos estudantes no seu percurso académico, mas também como cidadãos capacitando-os para a aprendizagem ao longo da vida (Iannuzzi, 1998; Winner, 1998; Hardesty, 1999; Raspa y Ward, 2000; Rader, 2004). O certo é que, se em alguns países esta necessidade é já uma realidade não se passa o mesmo noutros, como em Portugal, onde o trabalho colaborativo entre professores e bibliotecários resulta mais de iniciativas individuais do que de linhas de trabalho definidas pela gestão de topo que envolvam os dois grupos. Entendemos assim que "Librarians still need to be accepted and trusted by users, especially by academic staff, many of whom make greater use of colleagues and informal contacts to obtain information." (Jordan, 1998, p. 99).

Existe igualmente extensa literatura que descreve as dificuldades que essa colaboração enfrenta e que decorrem, em nossa opinião, de duas causas principais: comunicação muito escassa entre os dois grupos e consequente desconhecimento, da parte dos professores, quanto aos conhecimentos, capacidades e competências, bem como quanto aos distintos domínios de actuação dos bibliotecários. Em 1969, Marchant apontava como primeira fonte importante de conflito entre bibliotecários e professores o acesso dos estudantes a estas unidades, reservadas nos séculos XVIII e XIX, sobretudo aos professores. $\mathrm{O}$ acesso dos estudantes aos livros constituía assim uma ameaça ao controlo que os professores exerciam sobre os estudantes e sobre os seus recursos para aprender. Para outros professores, a biblioteca existe essencialmente para apoiar as suas actividades de investigaçáo manifestando alguma dificuldade em aceitar as normas existentes, que regulam a utilização dos recursos de informação existentes e que os impedem de os utilizar como se fossem seus (Biggs, 1981, p. 186). Outros ainda, não recorrem aos bibliotecários pois sentem-se humilhados por pedir ajuda alguém que consideram que desempenha um papel de apoio e, por isso, subordinado, o que diminui a importância e a relevância do seu trabalho aos seus olhos (Farber, 1999, p. 230). São também referidos aspectos como a divergência quanto ao peso que cada grupo deve ter nas questôes relativas à selecção e aquisição de documentos e à gestão da própria biblioteca; diferentes pontos de vista relativamente à missão e objectivos da biblioteca; a ausência de informação, da parte dos professores, quanto às qualificações académicas e à formação profissional dos bibliotecários; a autonomia profissional e a liberdade académica dos professores que os levam a opor-se à participação dos bibliotecários na formaçâo dos estudantes; a falta de tempo; e a cultura dos professores, que valoriza mais a investigação, o conteúdo, a especialização, atribuindo menos valor ao ensino, ao processo de aprendizagem e aos estudantes. Também os estereótipos dos bibliotecários, com expressão na literatura e no cinema, não facilitam o relacionamento entre os dois colectivos já que "the term 'librarian' connotes an antiquated understanding of what we do and inadequately represents our capabilities." (Weir, 2000, p. 2)

Do lado dos bibliotecários, é referido o seu isolamento bem como o facto de comunicarem demasiado entre eles esquecendo ou evitando a construção de canais de comunicação com os professores. Algum receio, o seu agrado com pequenos avanços 
que vão concretizando, a ausência de tempo, de recursos, e de apoio por parte da gestão de topo bem como a dificuldade que os bibliotecários têm em compreender a cultura do campus são apontados como aspectos que podem explicar as dificuldades que os bibliotecários sentem para desempenhar o seu papel de formadores/educadores nas instituiçóes de Ensino Superior (Kempcke, 2002, p. 539-540). Por outro lado, e na linha da investigação desenvolvida, é nossa convicção que não podemos partir do princípio que os professores sabem o que fazemos e do que somos capazes. Temos de, em cada oportunidade de interacção, encontrar a forma mais adequada para pormos em destaque as nossas competências. Trata-se de concretizar um conjunto de iniciativas enquadradas no domínio do marketing da profissáo, com especial ênfase no marketing dos relacionamentos.

Existe, contudo, uma necessidade evidente, por parte dos estudantes e dos professores, de uma melhor e maior capacidade de acesso e utilização da informação, o que obriga os bibliotecários a envolver-se mais em actividades de docência, por exemplo em actividades de formação em literacia informacional. Os professores reconhecem que a Internet coloca desafios educativos para os quais não dispóem nem do tempo nem do conhecimento especializado para se manter actualizados. Por esta razão, os bibliotecários devem desenvolver programas que lhes permitam trabalhar estreitamente com os seus colegas professores, por exemplo, na integração da aquisição das capacidades de acesso e utilização da informação nos planos de estudo. É essencial que o ensino dessas competências integre o currículo sendo os bibliotecários e os professores responsáveis por garantir esse tipo de formaçáo "...so that each teaches the skills that their credentials best qualify them to teach.” (Grafstein, 2002, p. 202).

Raspa e Ward (2000) identificam três níveis de interacção entre bibliotecários e professores que distinguem segundo a sua duração e intensidade, a distribuição das tarefas e a partilha de objectivos comuns. O primeiro é denominado estabelecimento de contactos (networking), o qual não é mais do que uma forma de interacção pessoal pouco estruturada que consiste na troca de informação para benefício mútuo sem que exista um objectivo comum. O segundo tipo é a coordenação (coordination) que representa uma relação de maior complexidade entre as duas partes em que se identificou um objectivo comum, ainda que não exista partilha de actividades: cada uma das partes trabalha de forma separada para alcançar o objectivo. O último nível é a colaboração (collaboration) que implica o compromisso de cada uma das partes e o desenvolvimento de uma relação de trabalho a longo prazo, em que os participantes negoceiam e alcançam um consenso sobre as acções a desenvolver para alcançar o objectivo estabelecido. $\mathrm{O}$ trabalho é realizado pelas duas partes, sendo tomadas em consideração as competências e capacidades de cada uma. Este é o tipo de relação mais benéfico para bibliotecários e professores (p. 4-5).

A colaboração implica sermos flexíveis, darmos prioridade às necessidades dos utilizadores e encorajarmos a liderança e a inovação na equipa da biblioteca (Creth, 2000). Por outro lado devemos identificar parceiros tendo por objectivo o fornecimento de serviços que apoiem o ensino, a aprendizagem e a investigação. Isto significa, entre outras coisas: compreender o que é uma parceria, identificar novos parceiros e novas formas de trabalhar com parceiros já existentes e saber o que levamos para a parceria, isto é, o valor da biblioteca e a contribuição dos seus profissionais. Na mesma linha de pensamento Rice-Lively e Racine (1997) consideram que os profissionais de informação 
"...can no longer be constrained by the building in which they do most of their work. Collaboration must take place within the organization, within the institution, within the profession, across disciplinary and professional boundaries, and within the information industry." (p. 37). Uma parceria é mais do que trabalhar em conjunto para concretizar projectos. É uma atitude de criaçáo/descoberta partilhada.

\section{Conclusões}

O novo modelo de ensino-aprendizagem (Bolonha - EEES) traduz-se numa maior autonomia do estudante o qual deve desenvolver um conjunto de competências que lhe permitam aprender a aprender. Centra-se na aprendizagem e não na docência devendo o Ensino Superior contribuir para que o estudante adquira um conjunto de competências que lhe permitam ter êxito no seu percurso académico assim como no seu exercício profissional ao longo da vida. Assim, o professor é um guia que deve orientar o estudante na busca do conhecimento e no desenvolvimento das diferentes competências indispensáveis para que possa aprender a aprender, produzir novos conhecimentos e não simplesmente reproduzir as ideias de outros.

As bibliotecas universitárias convertem-se em espaços dinâmicos que incentivam a aprendizagem através do espírito crítico, do questionamento, da colaboração e da discussão de ideias e pontos de vista. Os novos desafios que se colocam às bibliotecas universitárias e aos seus profissionais não se solucionam com uma simples reorganização dos serviços. Exigem que a biblioteca esteja alinhada e vinculada a esse modelo de ensino-aprendizagem. O novo modelo de biblioteca universitária (information, learning, academic commons ou CRAI) deve ser entendido como um órgáo produtor de conhecimento e não como um órgão administrativo. Trata-se de uma nova concepção de biblioteca: deve participar em novas comunidades de aprendizagem, em novas formas de gestão e disseminação do conhecimento e na prestação de serviços para públicos mais diversificados e dispersos.

Os bibliotecários devem desempenhar práticas profissionais proactivas. Devem reflectir sobre o seu contexto profissional e sobre as instituiçóes nas quais desenvolvem essas práticas. Em consequência, têm de conceber, planear e executar os projectos e as actividades que mais contribuam para que as instituiçóes de que são parte possam concretizar a sua missão. Assim, os desafios que se colocam às Universidades influenciam a actuação das próprias bibliotecas e dos seus profissionais. O bibliotecário deve actuar como gestor de colecçóes, como produtor de metadados, como formador em literacia informacional e facilitador da aprendizagem, como fornecedor de serviços de referência virtuais, como gestor de relacionamentos, como gestor do conhecimento e editor de conteúdos, entre outros papéis. Esta diversidade exige a este profissional o desenvolvimento de várias competências e capacidades com recurso a conhecimentos de áreas como a Gestão, a Sociologia e o Marketing, entre outras. É igualmente necessário que o bibliotecário esteja disponível para assumir um papel de liderança no seio da Universidade pelo que deve conhecer a sua missão, valores e objectivos.

A colaboração entre bibliotecários e professores é inevitável neste novo modelo de ensino-aprendizagem devendo ambos articular a sua actuação em vários domínios devendo os serviços e produtos desenvolvidos e assegurados pela biblioteca servir para 
apoiar o processo de ensino-aprendizagem. Para tal, a dimensão da comunicação adquire uma relevância tão grande que não pode ser menosprezada. Trata-se de estabelecer uma rede de contactos úteis ao funcionamento da própria biblioteca e que promovam o seu posicionamento estratégico na instituição. Neste sentido, os bibliotecários devem converter-se em líderes e inovadores. Este tipo de actuação é indispensável numa época em que a gestão das bibliotecas é mais complexa (em termos técnicos e financeiros) e em que diminuem os recursos e aumentam as solicitaçôes.

A colaboração implica confiança e compromisso e, sobretudo, objectivos comuns. Os estudantes e o seu sucesso académico constituem, para bibliotecários e professores, um objectivo comum explicitado na própria missão das Universidades. O sucesso da colaboração entre estes dois grupos depende da compreensão dos preconceitos e das percepçóes que envolvem esta relação assim como das forças externas que orientam a colaboração multidisciplinar.

Neste sentido "The key challenge for librarians is to collaborate with academic colleagues to exploit the potential of information resources in programmes of study. (...) The key is for librarians to develop creative partnerships with academic staff. And this is where librarians come into their own. Networking with people of all kinds is essential for all aspects of library work - and we are very good at it!” (Bulpitt, 2001).

\section{Referências Bibliográficas}

Association of College and Research Libraries (2007). Changing roles of academic and research libraries. Retrieved January 10, 2008, from http://www.ala.org/ala/acrl/acrlissues/future/ changingroles.cfm

Adell, J. (2005, Novembro). Enseñar y aprender con tecnología en la Universidad del siglo XXI: ideología, tecnología y pedagogía. XIII Asamblea Geral de REBIUN. Retrieved May 2, 2008, from http://rebiun.uji.es/JordiAdell.ppt

Association of Research Libraries (1999). Keystone principles. Retrieved May 18, 2009, from http://www.arl.org/bm doc/keystone.pdf

Biggs, M. (1981). Sources of tension and conflict between librarians and faculty. The Journal of Higher Education, 52 (2), 182-201.

Bulpitt, G. (2001). From Library to Learning Centre: the experience of UK universities. In $7^{\circ}$ Congresso Nacional de Bibliotecários, Arquivistas e Documentalistas: actas. Lisboa: APBAD.

Cabo Rigol, M., \& Espinós Ferrer, M. (2004, November 2-5). Bibliotecarios e informáticos: sumando esfuerzos, aprendiendo juntos. Paper presented at the IX Congreso Internacional del CLAD sobre la reforma del Estado y de la Administración Pública. Retrieved December 3, 2007, from http://www.clad.org.ve/fulltext/0049669.pdf

Comisión Europea (2003). Comunicación de la Comisión El papel de las universidades en la Europa del conocimiento, COM (2003) 58 final. Retrieved August 8, 2007, from http://eur-lex. europa.eu/LexUriServ/site/es/com/2003/com2003_058es01.pdf

Conselho Europeu de Lisboa (2000). Conclusóes da Presidência, 23 e 24 de Março de 2000. Retrieved August 27, 2007, from http://www.estrategiadelisboa.pt/document/ 1137071987W5xLJoi20o82MT9.pdf

Creth, S. D. (2000). Information commons: a path to redefining services \& role of academic libraries. Retrieved October 2, 2006, from http://unc.edu/ pittma/InfoCommons/CrethNotes/pdf 
Doskatsch, I. (2003). Perceptions and perplexities of the faculty-librarian partnership: an Australian perspective. Reference Services Review, 31 (2), 111-121.

Farber, E. (1999). Faculty-librarian cooperation: a personal retrospective. Reference Services Review, 27 (3), 229-234.

Grafstein, A. (2002). A discipline-based approach to information literacy. The Journal of Academic Librarianship, 28 (4), 197-204.

Hardesty, L. (1999). Reflections on 25 years of library instruction: have we made progress? Reference Services Review, 27 (3), 242-246.

Hutchins, E. O. (2005). Building strong collaborative relationships with disciplinary faculty. In G. M. Gregory (Ed.), The successful academic librarian: winning strategies from library leaders (pp. 13-29). New Jersey: Information Today, Inc.

Iannuzzi, P. (1998). Faculty development and information literacy: establishing campus partnerships. Reference Services Review, 26, 97-116.

Jordan, P. (1998). The academic library and its users. Aldershot, England; Brookfield, USA: Gower.

Kempcke, K. (2002). The art of war for librarians: academic culture, curriculum reform, and wisdom form Sun Tzu. Libraries and the Academy, 2 (4), 529-551.

López Gijón, J. et al. (2006). La biblioteca universitaria como apoyo al aprendizaje en el Espacio Europeo de Enseñanza Superior. R. Eletr. Bibliotecon. Ci. Inf., no esp., 63-81. Retrieved March 19, 2008, from http://eprints.rclis.org/archive/00012680.

Marchant, M. P. (1969). Faculty-librarian conflict. Library Journal, 94, 2886-2889.

Moscoso castro, P. (2003, May 7-9). La nueva misión de las bibliotecas universitarias ante el Espacio Europeo de Enseñanza Superior. Paper presented at the II Jornadas REBIUN. Retrieved March 8, 2007, from http://biblioteca.uam.es/documentos/Jornadas_REBIUN/4\%20$\% 20$ nueva_mision_bibliotecas.pdf

Moscoso Castro, P. (2006). Las bibliotecas universitarias ante el nuevo marco de las enseñanzas. Boletin de la ANABAD, 56 (1), Retrieved March 21 2007, from http://hdl.handle. net/10017/804.

Orera Orera, L. (2007). La biblioteca universitaria ante el nuevo modelo social y educativo. El profesional de la información, 16, 4, 329-337.

Owusu-Ansah, E. (2007). Beyond collaboration: seeking greater scope and centrality for libray instruction. Libraries and the Academy, 7 (4), 415-429.

Rader, H. B. (2004). Building faculty-librarian partnerships for information fluency: the time for sharing information expertise is now. College \& Research Libraries News, 65, 74-76.

Raspa, D. \& Ward, D. (Eds.) (2000). Listening for collaboration: faculty and librarians working together. In D. Raspa \& D. Ward (Eds.), The collaborative imperative: librarians and faculty working together in the information universe (pp. 11-18). Chicago: Association of College and Research Libraries.

Rice-Lively, M. L., \& Racine, J. D. (1997). The role of academic librarians in the era of information technology. The Journal of Academic Librarianship, 23, 31-41.

Roes, H. (2001). Digital libraries and education. D-Lib Magazine, 7 (7/8). Retrieved March 9, 2001, from http://www.dlib.org/dlib/july01/roes/07roes.html.

Silva, A. M., Fernández Marcial, V. \& Martins, F. (2007). A literacia informacional no Espaço Europeu de Ensino Superior: fundamentos e objectivos de um projecto em várias fases. In $9^{\circ}$ Congresso Nacional de Bibliotecários, Arquivistas e Documentalistas: Actas. Lisboa: APBAD. 
Simão, J. V., Santos, S. M. \& Costa, A. A. (2003). Ensino superior: Uma visão para a próxima década ( $2^{\text {nd }}$ ed.). Lisboa: Gradiva.

Stoffle, C. et al. (2000). Predicting the future: what does academic librarianship hold in store? College and Research Libraries News, 61 (10), 894-897.

Weinberg, M. L., et al. (2005). How can academic librarians create value? Advances in Library Administration and Organisation, 22, 297-314.

Weiner, S. (2009). The contribution of the library to the reputation of the university. The Journal of Academic Librarianship, 35 (1), 3-13.

Weir, A. (2000). The Information Professional of the future: what skills will be needed and how will they be acquired? Retrieved September 24, 2008, from http://conferences.alia.org. au/alia2000/proceedings/aileen.weir.html

Winner, M. C. (1998). Librarians as partners in the classroom: an increasing imperative. Reference Services Review, 26, 25-29. 